\title{
The Effectiveness of Cognitive Load and Internal Motivation on the Performance in Study Skills
}

\author{
Dr. Omar Abdallah Khawaldeh ${ }^{1}$ Dr. Mamon Saleem Al-Zboun ${ }^{2}$ \\ 1. The Ministry of Education \\ 2. University of Jordan
}

\begin{abstract}
The current study aims to identify the effect of each of the levels of cognitive load and internal motivation and interaction among them on performance in the following study skills (receiving information, understanding information, storing information, and retrieving information). The study's basic sample consisted of (116) male and female $11^{\text {th }}$-grade students in Amman schools in Jordan. The study instruments included the cognitive load measure prepared by Mohammed Neama and Najeh Mamouri, 2015, and developed the researchers, the motivation test for Learning prepared by de Gopal Rao, 2004 and developed by the researchers, and the receiving information measure prepared by Ibrahim Sayed Samadouni, 1990 and developed by the researcher, and the understanding information measure prepared by Yahya Qasem; Fahmy Fadel, 2014 and developed by the researchers), and the storing information measure prepared by Adel Hussein, 2001 and developed by the researchers, in addition to the students' grade point average (GPA) as an indicator for retrieving information. The results found that there is a statistically significant effect of levels of cognitive load on the skill of storing information in favor of the low level. It also shows that there is a statistically significant effect of the levels of internal motivation on the skills of understanding information and storing information in favor of the high level. Besides, it shows that there is a statistically significant interaction of the effect of the cognitive load and the internal motivation on the information retrieving skill in favor of the high cognitive load with the high internal motivation, and the low cognitive load with the low internal motivation.
\end{abstract}

Keywords: information processing methods, cognitive load, internal motivation, study skills.

DOI: $10.7176 / \mathrm{JEP} / 11-4-10$

Publication date: February $29^{\text {th }} 2020$

\section{Introduction}

The contemporary age in which we live is characterized by change and rapid development in various aspects of life. One of the areas that witness a remarkable development in the educational field, as the scientific, technological, and cognitive development has led to a qualitative shift in this field, due to the rush of the educational field towards technology. Information and knowledge have become one of the basic resources in this field, in an effort by educators to obtain information quickly and at low cost as computers, software and communication networks helped to provide information at the required time. One of the recommendations of the educational conference held in Jordan in 1987 is focusing on the knowledge economy that only can be achieved by employing an effective technology in the educational field.

Education mainly aims to help learners achieve comprehensive and integrated growth through the educational system with all its components; the teacher, the learner, the curriculum, the surrounding environment, teaching strategies, goals, and through the fruitful interaction among these components, especially the interaction between the teacher as the leader, the guide, the facilitator in the educational situation, and the learner as the beneficiary, participant and target of the educational process, and the curriculum - in its broad sense - as the mirror that reflects the conditions of society and its goals, and translates its political, economic and social systems and trends in which young people live (Abdul Hadi (2007, p. 69).

Education still suffers in some educational environments from the control of traditional theoretical education based on the philosophy of spoon-feeding direct teaching. In these educational fields, the teacher is the first source of knowledge, and this may not be a flaw in education itself as much as it is a problem in the level of implementation by teachers, which is due to lack of seriousness at work or poor planning and preparation, adopting a short educational philosophy, and following educational views unsuitable for every time or place. This deficiency may appear more clearly in educating students on the policy of closed mind and restricting their role in receiving and implementing without discussing or examining what they receive; thus depriving them of one of the most important blessings that God Almighty has distinguished them from his other creatures, which is the mind and its harnessing to achieve its goals (Hamadan, 2005).

The learning process is not considered an easy and simple process, as this process is characterized as one of the complex processes that overlap in its formation by several factors, and many cognitive and mental processes. Of note, no learning educational process will occur unless the learner has factors, conditions, and strengths that motivate and direct him towards learning and requesting academic achievement, and these powers may be an 
internal or external factor stemming from the learner pushing him towards learning, and this is known as the motivation for learning. The latter is considered one of the basic conditions that help in achieving learning goals in the areas of learning, where the motivation for learning is a distinct case of general motivation that raises an internal knowledge state of the learner that leads him or her to pay attention to learning situations and actively accept them until learning is achieved (Qattamy and Adas, 2002).

One of the features of the contemporary era is that it differs from the previous one, as knowledge and information have become an industry that attracts huge investments to collect information and transform it from its raw form into information services. The products of this era have become more dependent than ever on advanced information technology. The sources of power and influence in the world have changed from ownership of strategic materials to ownership of the information that has become a source of strength and progress. (Musa and Mubarak, 2005).

Abdel Nasser and Baden (2014) state that one of the most important reasons for the weakness of school education is the low ability of learners to process information, which makes them unable to invest their minds when they read, listen and discuss. Their weak ability to attain academic achievement is not necessarily due to a low degree of intelligence or a lack of effort and inclination to study, but due to their low skill level in organizing and processing information and their lack of knowledge of methods of preparing and processing information.

Another factor that affects human learning and behavior is motivation, as it has a significant impact on the excitement of learning among students, and this is what has been mentioned in the 2004 study of Rimawi that people with high motivation achieve greater success in school and obtain various promotions, jobs, and successes more than people with low motivation. Also, the founders of cognitive theory focused on the field of motivation and found that how the individual thinks about what happens to him determines the extent of his repetition and perseverance on certain behavior in subsequent situations. Likewise, the student's reaction to a certain degree in the exam is partly based on his previous performance in the exam (Zaqq, 2009).

Similarly, the theory of cognitive load is concerned with the size of information in the short-term memory and studying how to reduce the cognitive load for the learner, so that he can achieve the greatest amount of learning. In light of this, two results have been reached; the first is to build educational designs according to the cognitive structure of learners, and the second is to develop the capabilities of learners and help them develop cognitive structures and deal with knowledge and information through the use of strategies that expand the limits of their working memory, and then reduce the learner's cognitive load. One of the methods used to reduce the learner's cognitive load is to display part of the visually designed educational material, as this will enhance the learning process and help to develop the individual's imaginations, find creative ideas for him, and increase his ability to analyze, understand and store (Abu Rayash, 2007).

Pintrich \& Schunk point out that students can improve their motivation when they learn in an environment that encourages independence, in which challenge, curiosity, control, imagination, student involvement in learning processes, and responsibility for their learning are developed. In light of the vital interaction of the interactive board in learning and teaching, the usual methods of evaluation are no longer in harmony with modern educational philosophy, and thus it has become necessary to follow teaching methods associated with modern evaluation methods such as real evaluation, which leads to increases students' motivation to have an independent learning, develop their skills, and help them to use their learning through what is given by the teachers to students such as the real evaluation processes that include many activities and practical presentations, which would provide good information on students' progress (Masood, 2008).

Those concerned with the educational process have paid attention to academic achievement because of its importance in the life of the student, and its crucial educational outcomes, as the achievement is an essential criterion for most of the decisions related to the student, curriculum, and educational process. Through it, the progress of students in the study and their distribution to the different types of education are also identified, as well as their choice of the educational programs that suit them. Besides, the academic achievement in its cognitive, skill and emotional aspects affects the formation of the student's personality and determines the degree of its academic and social status (Irtahi, 1993).

Educational institutions are also concerned the academic achievement as an indication of their progress towards educational goals. The achievement measures the educational outcomes that the institutions seek to achieve. Moreover, educational institutions strive to make their students attain a high level of achievement because the level of achievement indicates the adequacy of these institutions and their ability to reach their goals (Abu Haija, 1997).

Also, some factors influence academic achievement, including internal factors, which are the cognitive and psychological characteristics of the student that distinguishes him from others, and external factors, which are the environment surrounding the student, and these factors have a role in his success or failure. One of the most important internal factors is motivation, the concept of self and intelligence, and habits of the mind, cognitive capabilities, and his ability to control and direct his emotions. As for external factors, the most important factors 
are the educational institution and its positive or negative impact on the student, the extent of importance and interest given to the student, and the level of his psychological adoption (Adas, 1999). Therefore, this study aims to examine the effect of each of the contents of the cognitive load and the internal motivation on performance in the study skills.

\section{Problem of the Study}

The knowledgeable person with an insight into the current educational reality in the Hashemite Kingdom of Jordan notices the traditional pattern that almost overwhelms many teaching methods, and the majority of these methods only focus on minimum thinking skills, and rarely rise to develop higher thinking skills. Because higher-order thinking skills are of great importance in bringing up a thoughtful, knowledgeable, and openminded generations who are aware of what is happening in their surroundings if they are smoothly taught and developed according to sound scientific foundations, a real need to develop the student's thinking styles and skills has finally emerged (Hamadan, 2005).

Despite scientific and technological progress in all fields, including the educational field, the teaching methods that are still used in schools depend to a large extent on spoon-feeding direct and provide the student with knowledge and skills of thinking and problem solving without being the focus of the teaching and learning process, where the greatest load falls on the teacher who has the largest role in student education. Many scientific processes are based on memorization away from employing different thinking methods, which has negatively affected the achievement of students in general (Abu Farah and Alyan, 2008).

The research problem also has emerged from the fact that there are many difficulties that students face due to large information and its overlapping. This overlapping requires high attention by students and the processing of this information during a specific period. This leads to memory fatigue even though the limited working memory capacity does not absorb it, leading to an increased cognitive load resulting from large information and its interaction, affecting the educational learning process. This also requires finding an effective strategy through which information can be received and processed with the lowest possible cognitive load, which contributes to transferring the impact of learning because reducing the cognitive load on working memory increases the effectiveness of the learning and teaching process and activates students' use of different thinking levels.

Many studies have also indicated that the level of motivation among students is not at the highest level, and this may be due to many reasons such as the nature of the subject matter and teaching methods used by teachers and factors related to the school infrastructure, and other matters that reduce students' motivation towards learning and achieving success in the different school subjects such as the 2008 study of Yamani .

Because of the great momentum in the use of information technology in the various education departments, this led to the emergence of the so-called information load, which means a clear increase in the use of technology with a negative impact in the application or benefit from this technology in obtaining the necessary information and data in this field, and this has been mentioned by many researchers such as the 2010 study of Najjar and other researchers. In light of the lack of studies dealing with the impact of both levels of cognitive and internal motivation on performance in study skills, this has prompted the researchers to study this topic and area to attain results that may benefit those interested in this field.

\section{Questions of the Study}

In light of the study problem, the main question of the study is "What is the effect of each of the methods of processing information, levels of cognitive load and internal motivation on performance in study skills?" This question is divided into the following set of questions:

1. Is there an effect of levels of the cognitive load on performance in study skills (receiving information, understanding information, storing information, and retrieving information)?

2. Is there an effect of the levels of internal motivation on performance in study skills (receiving information, understanding information, storing information, and retrieving information)?

3. Is there an interaction between the cognitive load and the internal motivation in their effect on the skill of receiving information, the skill of understanding information, the skill of storing information, and the skill of retrieving information?

\section{Objectives of the Study}

The following objectives are formatted to answer the questions of the study.

1. Exploring the effect of the levels of cognitive load on performance in study skills (receiving information, understanding information, storing information, and retrieving information)

2. Identifying the effect of the levels of internal motivation on performance in study skills (receiving information, understanding information, storing information, and retrieving information).

3. Examining the interaction between the cognitive load and the internal motivation in their effects of the skill of receiving information, the skill of understanding information, the skill of storing information, and the skill of 
retrieving information.

\section{Significance of the Study}

The importance of research stems from the practical aspect of being trying to identify the impact of each of the levels of cognitive load, internal motivation on performance in study skills at a time when these schools' reliance on knowledge has become a basis for carrying out their competitive role at the national and global levels, along with the positive effects to support this competitive position. The researchers believe that the study results will contribute to clarifying the impact of each of the methods of information processing, levels of cognitive load, and internal motivation on performance in study skills and that knowledge of this effect will contribute to preparing managers in those secondary schools to deal with a large amount of information in a better way. Also, the recommendations, suggestions, and techniques of the study will contribute to reducing this phenomenon and its negative effects on secondary schools in Jordan.

\section{Terms of the Study} First: Cognitive Load

The levels of the cognitive load are procedurally defined as the degree obtained by students through their response to the items of the cognitive load used in this research.

Second: Internal Motivation

It is procedurally defined as the degree obtained by the students on the internal motivation test used in this research.

\section{Third: Study Skills}

They are procedurally defined as the degree obtained by students on a measure of study skills used in this research.

\section{Limits of the Study}

The limits of the current study are as follows:

1. Objective limits: The application of the study is limited to measure the effectiveness of both methods of information processing, levels of cognitive load and internal motivation on performance in study skills.

2. Time limits: The study is applied to the academic year (2018/2019).

3. Spatial limits: The application of the study is limited to secondary schools in Amman, Jordan

4. Human limits: The application of the study is limited to a random sample of high school students in Amman, Jordan.

\section{Previous Studies}

There are few studies conducted on the area of methods of information processing, levels of cognitive load, and internal motivation on performance in study skills. In his 2010 study entitled "Relationship between Cognitive Load, Task Complexity, and Indicators of Plagiarism: Implications for Instructional Design", Garnica defines the relationship between the cognitive load as measured by the cognitive load measure and one of the indicators of imitation of writing style, as well as studying the relationship between the cognitive load, degree of the complexity of the task and one of the indicators of imitating the writing method. the study sample consists of (53) university students, and the measures of cognitive load and imitation of writing style are applied to the participants. The results of the study show that there is a statistically significant correlation between the high cognitive load and the tendency to imitate the writing style, and the degree of complexity of the task.

In his 2010 study entitled "Exploring the Influence of Information Overload on Middle Management Decision Making In Organizations", Carlevale aims to explore the impact of the increased information load on decision-making in organizations. The study is conducted by XYZ company in California, USA, and the review unit consists of (22) managers from middle departments. The study found that technology causes the load of information resulting from the huge amount of daily e-mails, which has caused more pressure to managers. The results also show that the cognitive load resulting from dealing with technology hinders the decision-making process. In another 2010 study entitled "A Study of University Student's Motivation and its Relationship with their Academic Performance", Afzal and et al. aim to reveal the level of motivation of university students and their relationship to academic performance. To achieve the goals of the study, the researcher used the academic motivation measure, and the study sample consists of (342) male and female Pakistani students from different universities. The results of the study show a correlation between internal motivation and academic performance. In another 2014 study entitled "The Effect of Training on Studying Skills in Internal Motivation, Achievement and Academic Skills for Eighth Grade Students in Jordan", David aims to identify the impact of training on studying skills in internal motivation and academic achievement, and academic skills of (144) students from eighth-grade students in Jordan. To attain the goal of the study, a measure of study skills is developed, along with the use of internal motivation measures. The study shows that there is a significant impact of training on effective study 
skills, high internal motivation skills, academic achievement, and study skills.

Moreover, in another 2014 study entitled "Cognitive Methods and Academic Self-Efficiency as Predictors of the Cognitive Load of High School Students in Mafraq District", Khawaldeh aims to reveal the relative and predictive ability of both cognitive methods and academic self-efficacy in the cognitive load of (447) male and female high school students in the public schools in the Mafraq District. To achieve the goals of the study, a cognitive methods measure is prepared by Martin in 1983 and the self-efficacy measure is prepared by Badarine in 2008. To measure the cognitive load, two methods are used, the first is Pass psychometry of 1992, and the second is the short-term visual memory test using a computer application program. The study results show that there is a statistically significant predictive ability of cognitive methods by cognitive load.

In another 2019 study entitled "Self-Pity and Cognitive Load as Predictors of Learning Stress for Female Students in the College of Education in New Valley", Waer aims at examining the relationship of learning stress with both: self-pity and the cognitive load, and predicting learning stress from self-pity and the cognitive load among female students of the second year at the College of Education in the New Valle. The research sample consists of (191) female students from the second-year students at the College of Education in the New Valley. Three measures are applied to them as follows: (educational stress, self-pity, and cognitive load). The study shows that there is no statistically significant correlation between educational stress and self-pity, and there is a statistically significant correlation between educational stress and cognitive load. It also shows that educational stress can be predicted from self-pity and cognitive load in the study sample.

In light of the related previous studies, it has been found that the majority of students in pre-university education, especially the secondary stage, suffer from a high cognitive load due to the nature of the school life. Also, some studies indicate that there is a positive and statistically significant correlation between the cognitive load and each of: (task difficulty, degree of task complexity, stress generation, level of learning disability, and educational stress. Besides, other studies indicate that there are negative correlations and statistically significant relationships between the cognitive load and each of these elements of the decision-making process, kinesthetic learning style, academic self-efficacy, cognitive skills, first-degree cognitive control power, and critical thinking skills. Moreover, the study has found that there are statistically significant differences between low and high cognitive load in both critical thinking skills, cognitive skills, and academic self-efficacy) in favor of the low cognitive load.

\section{Methodology of the Study}

1. Methodology

In light of the aforesaid objectives, questions, and hypotheses, the current research necessitates the use of an analytical descriptive approach to verify the validity of the study hypotheses and answer their questions, where the researcher used arithmetic means and standard deviations for the responses of the sample members to the study variables. The analysis of variance is also used to identify the effect of the interaction among all independent variables (methods of Information processing (superficial - deep), cognitive load measure (high low), internal motivation (high - low), and performance in study skills for a sample of $11^{\text {th }}$-grade students in the Hashemite Kingdom of Jordan.

\section{Study Sample}

\section{a. A study sample verifying the psychometric properties}

The study sample consists of (200) male and female students from the $11^{\text {th }}$-grade students enrolled in Amman city schools. This sample is used to calculate the psychometric properties of the study instruments and to ensure the availability of validity and reliability criteria and their suitability for application to the basic sample.

\section{b. Basic Study Sample}

The basic study sample consisted of (116) male and female students from the $11^{\text {th }}$-grade students in Amman city schools in the Kingdom of Jordan, and their ages ranged between 16-17 years. The sample is distributed according to each of the independent variables into several groups determined according to the following table: Table 1: Distribution of Basic Sample Individuals According to Each of the Methods of Information Processing , Cognitive Load Level, and Internal Motivation Level

\begin{tabular}{|l|l|l|l|l|}
\hline \multirow{2}{*}{$\begin{array}{l}\text { Dependent } \\
\text { variables }\end{array}$} & Cognitive Load & Internal Motivation \\
\cline { 2 - 5 } & High & Low & High & Low \\
\hline Number & $\mathbf{5 9}$ & 57 & 51 & $\mathbf{6 5}$ \\
\hline Percentage & $\% 50.86$ & $\% 49.14$ & $\% 43.97$ & $\% 56.03$ \\
\hline Total & 116 & 116 & \\
\hline
\end{tabular}

\section{c. Study Instruments}

1.Cognitive Load Measure Brepared by Mohammed Neama and Najeh Mamouri, 2015 and Developed by the Researchers.

\section{Measure Description}

The measure in its initial form consists of (8) specific questions with a period, which measures the cognitive load 
level (high - low) for 11th-grade students in Amman schools in Jordan, and determines the extent of their ability to encode the presented information and the extent to which it is stored in the working memory or not. In detail, each question is divided into one, two or three tasks and the student is required to answer these tasks at a specific time, so the student's degree for each of the questions ranges between 0 - 3 degrees. Thus, the weighted mean for each cognitive load level is determined according to Table (2).

Table 2: Weighted Means for Each Level of Cognitive Load

\begin{tabular}{|l|l|l|}
\hline \multirow{2}{*}{ Cognitive Load Level } & Weighted Mean for Total Degree \\
\cline { 2 - 3 } & Beginning of Level & End of Level \\
\hline High Cognitive Load & 0 & 12 \\
\hline Low Cognitive Load & 13 & 24 \\
\hline
\end{tabular}

Table (2) shows that there are two cognitive load levels: the low level and its degrees range between (13$24)$, and it reflects a high ability of students to deal with the presented information, code and store them in the working memory. It also included the high level of the cognitive load, and its degrees range between (0-12), which reflects the low ability of students to deal with the presented information, code and store them in working memory. The more the cognitive load is seen concurrently (exposure to large amounts of information), the lower the performance percentages will be in the processes of storing and recalling the information.

Psychometric Properties of the Cognitive Load Measure

First: Measure Validity

a. Criterion Validity

The researchers calculated correlation coefficients between the degrees of male and female students in the $11^{\text {th }}$ grade school through the cognitive load measure developed by the researchers, and the cognitive load measure prepared by Helmy Fil (2015), and this is showed in Table (3).

Table 3: Correlation Coefficients Between the Total Degree for the Cognitive Load Measure and the External Criterion

\begin{tabular}{|l|l|}
\hline Criterion / Measure & External Criterion \\
\hline Cognitive Load Measure & $* * 0.825$ \\
\hline
\end{tabular}

Table (3) shows that there is an increase in the values of correlation coefficients of the cognitive load measure developed by the researchers, along with the values of correlation coefficients of the cognitive load measure prepared by Helmy Fil (2015). In detail, the correlation value between the total degree of the measure and the total degree of the criterion reached $(0.825)$, which means that there is a statistically positive correlation at the level of significance ( 0.01$)$ between the cognitive load measure (developed by the researchers) and the cognitive load measure (criterion). This indicates the validity of the criterion for the cognitive load measure used in this research.

\section{- Internal Consistency}

Internal consistency has been used to explore correlation coefficients between the items of cognitive load measure and the total degree of the measure as showed in the following table:

Table 4: Correlation Coefficients for the Items of Cognitive load Measure and the Total Degree for the Measure

\begin{tabular}{|l|l|}
\hline Item & Total Degree of the Cognitive load Measure \\
\hline 1 & $0.511 * *$ \\
\hline 2 & $0.475^{* *}$ \\
\hline 3 & $0.586^{* *}$ \\
\hline 4 & $0.458^{* *}$ \\
\hline 5 & $0.535^{* *}$ \\
\hline 6 & $0.415^{* *}$ \\
\hline 7 & $0.610 * *$ \\
\hline 8 & $0.389 * *$ \\
\hline
\end{tabular}

Table (4) shows that there is an increase in the values of correlation coefficients for items of cognitive load measure and the total degree of the measure, where the values of correlation coefficients ranged between $(0.389$ and 0.610$)$, and all of them are statistically significant values at the level of significance $(0.01)$. This indicates the internal consistency of the measure and its applicability to the basic sample.

Second: Reliability of the Cognitive Load Measure

The researcher has calculated the reliability coefficients for the total degree of the measure in two methods: Cronbach-Alpha and the Split-half, as showed in Table 5. 
Table 5: Reliability of the Cognitive Load Measure in the Two Methods of Cronbach-Alpha and Split-Half

\begin{tabular}{|l|l|l|l|c|}
\hline Total Degree & No of Items & Cronbach-Alpha & $\begin{array}{l}\text { Split-Half } \\
\text { Guttman }\end{array}$ & Spearman-Brown \\
\hline Cognitive Load & 8 & 0.505 & 0.522 & 0.526 \\
\hline
\end{tabular}

Table (12) shows that there is an increase in the values of students' reliability coefficients of the total degree of cognitive load, where the Cronbach-alpha coefficient is $(0.505)$, and the Guttmann split-half reliability coefficient is $(0.522)$. By using the Spearman-Brown correction formula, the reliability coefficient reaches (0.526), indicating the reliability of students' degrees on the cognitive load measure and the suitability of using it with the basic study sample.

\section{The Final Form of the Measure}

The cognitive load measure in its final form consists of (8) specific questions with a period, which measures the cognitive load level for $11^{\text {th }}$-grade students in Amman schools in Jordan, and determines the extent of their ability to encode the presented information and the extent to which it is stored in the working memory or not. Each question is divided into one, two or three tasks, and the student is required to answer these tasks at a specific time. In the light of these tasks, the student is classified into a student with a low cognitive load whose degree on the measure as a whole ranges between 13-24, and a student with a high cognitive load whose degree on the measure as a whole ranges from 0-12.

\section{Motivation Test for Learning Prepared by De Gopal Rao, 2004 and developed by the Researchers. Measure Description}

The measure in its initial form consists of (20) items, which measures the internal motivation level for learning for $11^{\text {th }}$-grade students in Amman schools in Jordan. It has been created by selecting two possible alternatives (A and B) that complement the meaning, noting that both options are correct, but each option expresses the student's internal motivation type (low motivation - high motivation).

According to the answer to the measure items, the student gets one degree in the case of selecting an option that expresses the low internal motivation, and two degrees in the case of selecting an option that expresses the high internal motivation, and thus the total degree of the measurement ranges between $(20-40)$ degrees.

Table 6: Weighted Mean for Motivation Measure for Learning

\begin{tabular}{|l|l|l|}
\hline Internal Motivation Level & Weighted Mean for Total Degree \\
\cline { 2 - 3 } & Beginning of Level & End of Level \\
\hline High Motivation & $\mathbf{2 0}$ \\
\hline Low Motivation & $\mathbf{2 1}$ & $\mathbf{4 0}$ \\
\hline
\end{tabular}

Table (6) shows that there are two internal motivation levels for learning: the low level and its degrees range between $(1-20)$ degrees, expressing a weak readiness and low ability to learn. It also includes the high level of internal motivation to learn, and its degrees range between (21-40) degrees, expressing a high readiness and ability for students to learn.

\section{Psychometric Properties of the Internal Motivation Measure}

\section{First: Measure Validity}

\section{a. Criterion Validity}

The researcher calculated correlation coefficients between the degrees of male and female students in the $11^{\text {th }}$ grade school through the internal motivation for learning measure prepared by De Gopal Rao and developed by the researchers and Marcia Conner's 1993 motivation measure as shown in Table (7).

Table 7: Correlation Coefficients Between the Internal Motivation for Learning Measure and the External Criterion

\begin{tabular}{|c|l|}
\hline Criterion / Measure & Conner's Motivation Measure \\
\hline Internal Motivation for Learning & $* * 0.519$ \\
\hline *Significance at $0.05 \quad * *$ Significance at 0. & $\mathbf{N}=\mathbf{2 0 0}$
\end{tabular}

Table (7) shows that there is an increase in the values of correlation coefficients of Rao's internal motivation measure developed by the researchers and Conner's motivation measure, where the correlation coefficient value between the total degree of the measure and the total degree of the criterion reached $(0.519)$, and this means that there is a statistically positive correlation at the level of significance (0.01) between the internal motivation measure (0.01) between the internal motivation measure (developed by the researchers) and the motivation measure (criterion). This indicates the validity of the criterion for the measure developed by the researcher.

\section{- Internal Consistency}

Internal consistency has been used to explore correlation coefficients between the items of internal motivation measure and the total degree of the measure as showed in the following table: 
Table 8: Correlation Coefficients for the Items of the Internal Motivation for Learning Measure and the Total Degree for the Measure

\begin{tabular}{|l|l|}
\hline Item & Total Degree of the Cognitive load Measure \\
\hline 1 & $0.339 * *$ \\
\hline 2 & $0.406 * *$ \\
\hline 3 & $0.306 * *$ \\
\hline 4 & $0.512 * *$ \\
\hline 5 & $0.378 * *$ \\
\hline 7 & $0.409 * *$ \\
\hline 8 & $0.476 * *$ \\
\hline 9 & 0.126 \\
\hline 10 & $0.466 * *$ \\
\hline 11 & $0.554 *$ \\
\hline 12 & $0.552 * *$ \\
\hline 13 & $0.506 * *$ \\
\hline 14 & $0.482 * *$ \\
\hline 15 & $0.615 * *$ \\
\hline 16 & $0.441 * *$ \\
\hline 17 & 0.082 \\
\hline 18 & $0.586 *$ \\
\hline 19 & $0.436 * *$ \\
\hline 20 & $0.374 * *$ \\
\hline$*$ Significance at 0.05 & $0.457 *$ \\
\hline
\end{tabular}

Table (8) shows that there is an increase in the values of correlation coefficients for items of internal motivation for learning measure, as all of the values are statistically significant at the level of significance $(0.01)$ except for the items $(8,16)$ where their correlation coefficient is $(0.126,0.082)$ respectively, requiring the researcher to delete them so that the measure has an internal consistency

Second: Reliability of the Internal Motivation Measure

The researcher has calculated the reliability coefficients for the total degree of the measure in two methods: Cronbach-Alpha and the Split-half, as showed in Table 9.

Table 9: Reliability of the Internal Motivation Measure in the Two Methods of Cronbach-Alpha and Split-Half

\begin{tabular}{|l|l|l|l|l|}
\hline Total Degree & No of Items & Cronbach-Alpha & $\begin{array}{l}\text { Split-Half } \\
\text { Guttman } \quad \text { Spearman-Brown }\end{array}$ \\
\hline $\begin{array}{l}\text { Internal Motivation for } \\
\text { Learning }\end{array}$ & 18 & $\mathbf{0 . 7 6 9}$ & $\mathbf{0 . 6 9 4}$ & $\mathbf{0 . 6 8 4}$ \\
\hline
\end{tabular}

Table (9) shows that there is an increase in the values of students' reliability coefficients of the total degree of internal motivation, where the Cronbach-alpha coefficient is (0.769), and the Guttmann split-half reliability coefficient is (0.694). By using the Spearman-Brown correction formula, the reliability coefficient reaches (0.684), indicating the reliability of students' degrees on the measure and the suitability of using it with the basic study sample.

\section{The Final Form of the Measure}

The internal motivation measure in its final form consists of (18 items). It measures the level of internal motivation for learning for $11^{\text {th }}$-grade students in Amman schools in Jordan. This has been done by selecting two possible options (A and B) that complement the meaning. According to these options, the student is classified into a student with a low internal motivation whose grades on the measuring range between (1-18) degrees, and a student with a high motivation to learn whose grades on the measuring range between (19-36) degrees.

\section{Study Skills Measure}

\section{Measure Description}

The study skills measure in its initial form consists of four sub-measures aiming at identifying study skills, and they are defined as the ability of $11^{\text {th }}$-grade students to practice school activity well and as required. The study skills measure is applied to the survey sample, which is estimated by (200) male and female students from the $11^{\text {th }}$-grade school in Amman, Jordan. Below is an accurate description of each sub-measure of study skills:

First: Receiving Information Measure Prepared by Ibrahim Sayed Samadouni, 1990 and developed by the researcher.

The receiving information measure is considered as the first sub-skill of the study skills measure, as the quality of receiving information during the learning process represents an accurate objective indicator for focusing the attention required for the learning process. This measure includes two parts: 


\section{a. Pair Numbers Test (PNT)}

It is a table consisting of (9) consecutive rows, and each row contains a group of numbers having a multiplication relationship. The student is required to read the numbers horizontally, focus on each row, and place a circle on any two numbers whose product of the multiplication is equal to (20 or 30 or 40 ) out of each two horizontally consecutive numbers within two minutes. The student is given a degree for each of the horizontal grades of the test, and therefore the total degree for the pair numbers test ranges between 0-9 degrees.

\section{b. Letter Cancellation Test (SLCT)}

It is a table that contains the letters of the alphabet in a disorganized way. The student is required to focus well on the letters in each row and cross out any of the letters that form the word "Tourism" or the word "Home", and when he finishes from the first row, he moves to the second row and so on within two minutes. The student is given a degree for each of the horizontal grades of the test, and therefore the total degree for the Letter Cancellation Test ranges between 0-10 grades.

Second: Understanding Information Measure Prepared by Yahya Qasem and Fahmy Fadel, 2014 and Developed by the Researchers

The Information Understanding Skills Measure is the second sub-skill of the study skills measure and aims to identify the level of 11th-grade students in understanding the presented information presented. This measure consists of four questions:

The first question: It consists of four sub-questions of the multiple-choice type. The student is required to answer them in a one-minute period through a silent reading of some poetic verses and then place a correct sign in front of the correct choice. The student gets one degree in each question, Thus, the total degree for this question ranges between (0-4) degrees.

The second question: It consists of four essay sub-questions that the student answers in a three-minute period through an understanding of the read piece. The student gets one degree in each question, and thus the total degree for this question ranges between (0-4) Degrees.

The third question: It consists of four paragraphs that contain a number of wrong words. The student is required to underline the wrong word and define it in a one-minute period. The student gets one degree in each question, and thus the total degree for this question ranges between (0-4) degrees

The fourth question: It consists of four sub-questions of the fill-in blank type through reading some options, and the student must answer them within a two-minute period. The student gets one degree in each question, and thus the total degree for this question ranges between $(0-4)$ degrees.

Third: Storing Information Measure Prepared by Adel Hussein, 2001 and Developed by the Researchers. The information storing skill measure is considered to be the third sub-skill of the study skills measure and aims to identify the ability of the 11th-grade school students to store the largest amount of the presented information. This measure consists of four main tasks: numbers task, letter task, real words task, abstract words task, and meaningless words task. Each student is required to listen to each task and write down what he had heard in the place designated for each task. The student gets four grades for each task of the four tasks, and thus the total degree of the measurement ranges between $(0-16)$ degrees.

Fourth: Retrieving Information Measure: It is understood by the cumulative average of male and female degrees.

Table 10: Description of the Study Skills Measure and its Sub-Dimensions in its Initial Form

\begin{tabular}{|c|c|c|c|c|c|c|c|c|c|c|c|c|}
\hline $\begin{array}{l}\text { Measure } \\
\text { Dimensions }\end{array}$ & \multicolumn{2}{|l|}{ RIM } & \multicolumn{4}{|c|}{ UIM } & \multicolumn{5}{|c|}{ SIM } & $\begin{array}{l}\text { RIM } \\
\text { Retrieving }\end{array}$ \\
\hline $\begin{array}{l}\text { Sub- } \\
\text { questions }\end{array}$ & PNT & SLCT & Q1 & Q2 & Q3 & Q4 & NT & LT & RWT & AWT & MWT & \multirow{4}{*}{$\begin{array}{l}\text { It is } \\
\text { understood } \\
\text { by the } \\
\text { cumulative } \\
\text { average }\end{array}$} \\
\hline No of Items & 4 & 4 & 4 & 4 & 4 & 4 & 4 & 4 & 4 & 10 & 9 & \\
\hline $\begin{array}{ll}\text { Degree of } \\
\text { each } \\
\text { question }\end{array}$ & 4 & 4 & 4 & 4 & 4 & 4 & 4 & 4 & 4 & 0-10 & $0-9$ & \\
\hline & \multicolumn{2}{|l|}{$0-20$} & \multicolumn{4}{|c|}{$0-16$} & \multicolumn{5}{|c|}{ 0-19 } & \\
\hline
\end{tabular}

Study Hypothesis Validity Test

The results of the statistical analysis process related to the study variables and its descriptive and inferential statistics have been reviewed using the SPSS program.

Hypotheses Discussion

First and Second Hypothesis Validity Test

The first hypothesis states "There is a statistically significant effect of cognitive load levels on performance in study skills" as follows:

A- The skill of receiving information.

B- The skill of understanding information.

C- The skill of storing information. 
D- The skill of retrieving information.

To verify the validity of this hypothesis, the researcher calculated the Multivariate Analysis of Variance for each of the study skills: (receiving information, understanding information, storing information, and retrieving information) in light of cognitive load levels as showed in Table (11).

Table 11: Effect of Cognitive Load Levels on Performance in Study Skills

\begin{tabular}{|c|c|c|c|c|c|c|}
\hline $\begin{array}{l}\text { Source of } \\
\text { variance }\end{array}$ & $\begin{array}{l}\text { Dependent } \\
\text { variables }\end{array}$ & $\begin{array}{ll}\text { Sum } & \text { of } \\
\text { squares }\end{array}$ & $\begin{array}{l}\text { Degrees } \\
\text { freedom }\end{array}$ & $\begin{array}{l}\text { Mean of } \\
\text { squares }\end{array}$ & $\begin{array}{l}\text { Value } \\
\text { of F }\end{array}$ & $\begin{array}{l}\text { Significance } \\
\text { level }\end{array}$ \\
\hline \multirow[t]{4}{*}{$\begin{array}{l}\text { Cognitive } \\
\text { load levels }\end{array}$} & $\begin{array}{l}\text { Receiving } \\
\text { information. }\end{array}$ & 4.750 & 1 & 4.750 & 0.408 & $\begin{array}{l}\text { Not } \\
\text { significant }\end{array}$ \\
\hline & $\begin{array}{l}\text { Understanding } \\
\text { information. }\end{array}$ & 10.156 & 1 & 10.156 & 2.931 & $\begin{array}{l}\text { Not } \\
\text { significant }\end{array}$ \\
\hline & $\begin{array}{l}\text { Storing } \\
\text { information. }\end{array}$ & 18.489 & 1 & 18.489 & 4.512 & 0.05 \\
\hline & $\begin{array}{l}\text { Retrieving } \\
\text { information. }\end{array}$ & 211.564 & 1 & 211.564 & 2.468 & $\begin{array}{l}\text { Not } \\
\text { significant }\end{array}$ \\
\hline \multirow{4}{*}{\multicolumn{2}{|c|}{ Error }} & 1258.758 & 108 & 11.655 & & \\
\hline & & 374.167 & 108 & 3.465 & & \\
\hline & & 442.530 & 108 & 4.097 & & \\
\hline & & 9258.528 & 108 & 85.727 & & \\
\hline \multirow{4}{*}{\multicolumn{2}{|c|}{ Total }} & 27819.000 & 116 & & & \\
\hline & & 18473.000 & 116 & & & \\
\hline & & 29310.000 & 116 & & & \\
\hline & & 702644.000 & 116 & & & \\
\hline
\end{tabular}

Table (11) shows that there is no statistically significant effect of the cognitive load levels on the skill of receiving information, the skill of understanding information, and the skill of retrieving information as one of the study skills, as the calculated value of "F" is $(0.408,2.931,2.468)$ respectively, and all of the values are not statistically significant. It is also evident that there is a statistically significant effect of the cognitive load levels (high and low) on the skill of storing information, as the calculated value of " $F$ " is (4.512), which is statistically significant value at the level of significance 0.05 . With reference to the marginal means, it is clear that the differences are in favor of the low level.

The researchers show that there is a statistically significant effect of the cognitive load levels (high and low) on the skill of storing information in favor of the low level because the skill of storing information is one of the skills that require many mental processes such as attention and coding. In other words, these processes are greatly affected by the number of stimuli that the individual experiences. When there are many stimuli, it represents a high cognitive load to the student, making him unable to store information in short-term memory, and it is clear from this that there is a direct relationship between the amount of presented information and the cognitive load level. The cognitive load, through the theory of information processing, deals with everything related to memory and its types, as the working memory is the one that pays attention to the information and processes it for audio and visual elements. Also, it relates to the limited time that the information holds, as this limitation is behind the educational weakness, requiring to find the right strategies to counter them.

Moreover, the problem of cognitive load is closely related to working memory, as working memory is an active dynamic system because it focuses on dealing style and storage capacity at the same time, merging and translating previously stored information (Reddy et al., 2004, p15). In the working memory, the information industry is made in the sense that we are aware of its processing, and it is limited in the amount of information and the duration of focusing on it, and these two cases are directly proportional to the age at a certain point. The rate of keeping information in the working memory is between (18-36) hours, and we have the ability to change the way in which the information is processed every 2 seconds.

Therefore, the justification is clear in the relationship of influence and mutual influence between the low level of cognitive load and the skill of storing information in the memory, which confirms the incompatibility of the storage of presented information to the individual in the event of a high cognitive load. The result of this hypothesis is consistent with the results of many previous studies that dealt with the relationship of cognitive load levels with some other variables, including the 2002 study of Flad, which aimed to identify the impact of the increase in the cognitive load in the standards of self-decision and the bilateral tasks of mental effort during the problem-solving process. The results of the study indicated a positive correlation between the low cognitive load, self-efficacy, and difficulty of the task.

This result is consistent with the 2010 study of Carlevale, which aimed at exploring the impact of the information load on decision-making in organizations and technology companies. The results pointed to the information load resulting from the huge amount of everyday e-mail, causing managers more pressure. The 
results also show that the high cognitive load resulting from dealing with technology hinders the decisionmaking process. It is also consistent with the 2019 study of Waer, which aimed at examining the relationship of learning stress with both: self-pity and the cognitive load of university students. The study also shows that there is a statistically negative correlation between learning stress and self-pity, and the presence of a statistically significant correlation between learning stress and cognitive load.

In the light of the foregoing, the researchers see the necessity for the school to play its role entrusted in entrenching students with strategies for coding and storing information (such as segmentation, clustering, organizing information, and encouragement), and other strategies that enable students to obtain scientific material and deal with the vast amount of presented information inside the classroom and by recalling the courses.

\section{Third Hypothesis Validity Test}

The third hypothesis states "There is a statistically significant effect of the levels of internal motivation on performance in study skills" as follows:

A- The skill of receiving information.

B- The skill of understanding information.

C- The skill of storing information.

D- The skill of retrieving information.

To verify this hypothesis, the researcher calculated the Multivariate Analysis of Variance for each of the study skills: (receiving information, understanding information, storing information, and retrieving information) in light of the levels of internal motivation as showed in Table (12).

Table 12: Effect of Internal Motivation Levels on Performance in Study Skills

\begin{tabular}{|c|c|c|c|c|c|c|}
\hline $\begin{array}{l}\text { Source of } \\
\text { variance }\end{array}$ & $\begin{array}{l}\text { Dependent } \\
\text { variables }\end{array}$ & $\begin{array}{l}\text { Sum } \\
\text { squares }\end{array}$ & $\begin{array}{l}\text { Degrees } \\
\text { freedom }\end{array}$ & $\begin{array}{l}\text { Mean of } \\
\text { squares }\end{array}$ & $\begin{array}{l}\text { Value } \\
\text { of } F\end{array}$ & $\begin{array}{l}\text { Significance } \\
\text { level }\end{array}$ \\
\hline \multirow{4}{*}{$\begin{array}{l}\text { Internal } \\
\text { Motivation } \\
\text { levels }\end{array}$} & $\begin{array}{l}\text { Receiving } \\
\text { information. }\end{array}$ & 10.413 & 1 & 10.413 & 0.893 & $\begin{array}{l}\text { Not } \\
\text { significant }\end{array}$ \\
\hline & $\begin{array}{l}\text { Understanding } \\
\text { information. }\end{array}$ & 24.543 & 1 & 24.543 & 7.084 & 0.01 \\
\hline & $\begin{array}{l}\text { Storing } \\
\text { information. }\end{array}$ & 27.823 & 1 & 27.823 & 6.790 & 0.01 \\
\hline & $\begin{array}{l}\text { Retrieving } \\
\text { information. }\end{array}$ & 322.886 & 1 & 322.886 & 3.766 & $\begin{array}{l}\text { Not } \\
\text { significant }\end{array}$ \\
\hline \multirow{4}{*}{\multicolumn{2}{|c|}{ Error }} & 1258.758 & 108 & 11.655 & & \\
\hline & & 374.167 & 108 & 3.465 & & \\
\hline & & 442.530 & 108 & 4.097 & & \\
\hline & & 9258.528 & 108 & 85.727 & & \\
\hline \multirow{4}{*}{\multicolumn{2}{|c|}{ Total }} & 27819.000 & 116 & & & \\
\hline & & 18473.000 & 116 & & & \\
\hline & & 29310.000 & 116 & & & \\
\hline & & 702644.000 & 116 & & & \\
\hline
\end{tabular}

Table (12) shows that there is no statistically significant effect of the levels of internal motivation on the skill of receiving information, and the skill of retrieving information as one of the study skills, as the calculated value of "F" is $(0.893,3.766)$ respectively, and all of the values are not statistically significant. It is also evident that there is a statistically significant effect of the levels of internal motivation on the skills of understanding information and storing information as one of the study skills, as the calculated value of " $F$ " is $(7.084,6,790)$, respectively, and both of them have statistically significant values at the level of significance 0.01 . Concerning the marginal averages, it is clear that the differences are in favor of the high level.

The researchers show that there is a statistically significant effect of the levels of internal motivation (high and low) on the skills of understanding information and storing information as a study skill in favor of the high level because motivation is the primary driver of every human behavior, and internal motivation is defined as a behavior that stems from within the individual and pushes him to perform tasks and activities based on curiosity and interest. Therefore, it is natural and intuitive when study skills are affected and improved by the high internal motivation to learn, as it is a personal desire that expresses a state of readiness to acquire, understand, and retrieve information without any external pressures, practices or attempts to solicit students by teachers in the classroom. Decie believes that these two needs provide the individual with a driving force called internal motivation, and therefore self-motivated behavior satisfies the individual's need for independence, self-direction, and a sense of efficiency and effectiveness in dealing with the surrounding environment. Desai assumes that feelings of self-independence and efficiency are the internal promoters of self-driven behavior (Ryan \& Decie, 2006). 
(Qatamy, 2000) believes that the most important characteristic of students with a high internal motivation is the strong desire to accomplish and master the learning, as these students consider achievement and mastery an important source of self-realization. It is consistent with the 2010 study of Afzal, Ali, Khan, and Hamid, which aimed to reveal the level of motivation of university students and their relationship to academic performance. The results of the study show that the internal motivation has a positive impact on student achievement, along with the fact that the student average has increased by $(0.23-0.34)$ in favor of students with internal motivation.

It is also consistent with the 2011 study of Yao, Kan, and Cheng, which aimed to reveal levels of internal motivation toward study, curiosity, and external organization between females and males. The results of the study show that levels of internal motivation toward study, curiosity, and external organization among the students are similar and high in both genders. It is consistent with the 2018 study of Abdullah's study. The study aims to reveal the level of family functions, the level of emotional intelligence, and the level of internal academic motivation, in addition to identifying the predictive ability of family functions in emotional intelligence and academic internal motivation. The results show a positive correlation and a statistically significant relationship between each of the family functions, emotional intelligence, and academic internal motivation. The study also shows that emotional intelligence can be predicted through variables of the family's job performance and the level of academic internal motivation.

\section{Fourth Hypothesis Validity Test}

The fourth hypothesis states "There is a statistically significant interaction between the cognitive load and the internal motivation in their effect on the skill of receiving information, the skill of understanding information, the skill of storing information, and the skill of retrieving information.

To verify the validity of this hypothesis, the researcher calculated the Multivariate Analysis of Variance to find the effect of the interaction between cognitive load and internal motivation on performance in study skills as showed in Table (13).

Table 13: Effect of Interaction between Cognitive Load and Internal Motivation on Performance in Study Skills

\begin{tabular}{|c|c|c|c|c|c|c|}
\hline $\begin{array}{l}\text { Source of } \\
\text { variance }\end{array}$ & $\begin{array}{l}\text { Dependent } \\
\text { variables }\end{array}$ & $\begin{array}{l}\text { Sum } \\
\text { squares }\end{array}$ & $\begin{array}{l}\text { Degrees of } \\
\text { freedom }\end{array}$ & Mean of squares & $\begin{array}{l}\text { Value } \\
\text { of } F\end{array}$ & $\begin{array}{l}\text { Significance } \\
\text { level }\end{array}$ \\
\hline \multirow{4}{*}{$\begin{array}{l}\text { Cognitive } \\
\text { Load } \\
\text { *Internal } \\
\text { Motivation } \\
\text { B*C }\end{array}$} & $\begin{array}{l}\text { Receiving } \\
\text { information. }\end{array}$ & 2.529 & 1 & 2.529 & 0.217 & Not significant \\
\hline & $\begin{array}{l}\text { Understanding } \\
\text { information. }\end{array}$ & 4.766 & 1 & 4.766 & 1.376 & $\begin{array}{l}\text { Not } \\
\text { significant }\end{array}$ \\
\hline & $\begin{array}{l}\text { Storing } \\
\text { information. }\end{array}$ & 9.172 & 1 & 9.172 & 2.239 & Not significant \\
\hline & $\begin{array}{l}\text { Retrieving } \\
\text { information. }\end{array}$ & 681.932 & 1 & 681.932 & 7.955 & 0.01 \\
\hline \multirow{4}{*}{\multicolumn{2}{|c|}{ Error }} & 1258.758 & 108 & 11.655 & & \\
\hline & & 374.167 & 108 & 3.465 & & \\
\hline & & 442.530 & 108 & 4.097 & & \\
\hline & & 9258.528 & 108 & 85.727 & & \\
\hline \multirow{4}{*}{\multicolumn{2}{|c|}{ Total }} & 27819.000 & 116 & & & \\
\hline & & 18473.000 & 116 & & & \\
\hline & & 29310.000 & 116 & & & \\
\hline & & 702644.000 & 116 & & & \\
\hline
\end{tabular}

Table (13) shows that there is no statistically significant interaction of the impact of the cognitive load and internal motivation on the skill of receiving information, the skill of understanding information, and the skill of storing information. The calculated " $F$ " value is $(0.217,1.376,2.239)$, as all of the values are not statistically significant. While there is a statistically significant interaction of the effect of cognitive load (high, low) and internal motivation (high, low) on the skill of retrieving information, the calculated value of " $F$ " is (7.955), which is statistically significant value at the level of significance 0.01 . Referring to the table of marginal averages, we notice that the interaction in favor of a high cognitive load with high internal motivation, and a low cognitive load with low internal motivation.

The researchers show that there is a statistically significant interaction to the influence of the cognitive load and the internal motivation on the skill of retrieving information in favor of high cognitive load with high internal motivation, and low cognitive load with low internal motivation to the characteristics of individuals and learners. Individuals with a high internal motivation enjoy their and mastery of learning, as these students consider achievement and mastery important sources of self-realization.

\section{Recommendations}

In light of the current research results, the researchers recommends the following: 
1- Developing training programs in grade schools related to methods of processing information through meetings, training courses, and workshops.

2- Training students on how to face the cognitive load through the use of strategies to encode and store information.

3- Conducting more research that deals with raising the level of internal motivation as a cornerstone in pushing students towards higher academic learning and achievement.

4- Directing teachers to learn about the learning methods preferred by their students, because this helps the teacher select the learning media and methods of presentation appropriate for them.

5- Searching for the means and methods that reduce the level of the learner's cognitive load to achieve the highest degree of educational effectiveness.

6- Avoid using methods that increase the complexity of the educational subject that is presented to the learner not to increase the cognitive load among learners.

Fourth: Future Studies and researches:

In light of the results of the current study, the researchers recommend conducting the following future studies:

1- Study the differences in cognitive load levels amongst students of practical and theoretical departments.

2- The relationship of the learner's cognitive load levels to the teaching methods used by the teacher.

3- The relationship of the cognitive load levels with the level of performance in the oral and written tests.

4- making a comparative study of cognitive load levels among students who prefer cooperative learning and students who prefer competitive learning.

5- Studying the effect of strategies (direction, retention, and cognitive preference, acquiring concepts on academic achievement.

\section{References}

Abu Al-Haija, Khalid. (1997). The achievement level of the ninth grade students in biology in light of some variables. Master Thesis, Yarmouk University, Jordan.

Adas, Muhammad. (1999). Low school achievement: Its causes and treatment. Amman: Dar Al-Fikr for publication and distribution.

Abu Fara, Youssef, and Alian, Hamad. (2008). The role of knowledge management processes in the effectiveness of the activities of civil institutions in East Jerusalem. Research presented to the scientific conference held from September 25-28, Amman: University of Applied Sciences.

Afzal, H., Ali, I., Khan, A. \& Hamid, K. (2010). A Study of University Student's Motivation and its Relationship with their Academic Performance. International Journal of Business and Management, 5, 80-88.

Broussard, S. \& Garrison, M. (2004). The relationship between classroom motivation and academic achievement in elementary-school-aged children. Family and Consumer Sciences Research Journal, 33, 122-128.

Carlevale. E, (2010), Exploring the influence of information overload on middle management decision making in organizations, Doctoral Dissertation, University of Phoenix, Arizona, USA.

David, Ashraf. (2014). The effect of training on studying skills in internal motivation, achievement, and academic skills for eighth-graders in Jordan. Master Thesis, University of Jordan, Amman, Jordan

Flad, J. (2002). The effects of increasing cognitive load on self-report and dual-task measures of mental effort during problem-solving. A Doctoral Dissertation, University of Southern California.

Garnica, M. (2010). Relationship between cognitive load, task complexity, and indicators of plagiarism: Implications for instructional design. A Doctoral Dissertation at Capella University, Minnesota, USA.

Humaidan, Ibrahim bin Abdullah. (2005). Teaching and Thinking, Cairo: The Book Center for Publishing.

Irtahi, Bilal. (1993). The effect of both personality style and learning style on the academic achievement of tenth-grade students in Amman city. Master Thesis, University of Jordan, Amman, Jordan.

Khawaldeh, Mervat Salem. (2014). Cognitive methods and academic self-efficacy as predictors of the cognitive load of high school students in Mafraq, Master Thesis, College of Graduate Studies, The Hashemite University of Jordan.

Masoud, Mai. (2008). The effect of science teachers using the basic stage of real evaluation strategies on their students' understanding of scientific concepts and their ability to scientific thinking, Ph.D. thesis, University of Jordan, Amman.

Musa, Abdullah, and Mubarak, Ahmed, (2005). E-learning foundations and applications. Riyadh: Al-Homaidhi Press.

Qatamy, Youssef and Qatamy, Naifeh. (2000). Psychology of classroom learning. Amman: Dar El-Shorouk.

Qatamy Youssef, and Adas Abdel Rahman. (2002). General Psychology, Daman Dar Al Fikr for printing, publishing, and distribution.

Rimawi, Muhammad. (2004). General Psychology, Amman: Dar Al-Masirah.

Reddy, G.L. and Ramar, R. (2004). Relative effectiveness of video instruction in teaching social science to slow 
learners. Research Highlights, 1, 152-159.

Waer, Najwa Ahmed. (2019). Self-pity and the cognitive load as predictors of learning stress among students of the Faculty of Education in the New Valley. Educational Journal, Sohag University, 155-189.

Yamani, Abdul Karim . (2008). Learning and Teaching Strategies, Amman: Zamzam, Publishers.

Yau, H., Kan, M. \& Cheng, A. (2011). Gender differences in Intrinsic Motivation in Hong Kong Higher Education. E-Journal of Organizational Learning and Leadership, 9, 36- 57.

Zaqq, Ahmed. (2009). Psychology. Amman: Wael Press. 